$132 / 39295(2$

ENAL-TM- -1785

DE92 017736

FNAL-TM-178:

\title{
Gradient and Harmonic Field Measurements of the 4Q120 Quadrupole
}

\author{
Anthony J. Malensek \\ Fermi National Accelerator Laboratory \\ P.O. Box 500, Batavia, Illinois 60510
}

\section{DISCLAIMER}

\begin{abstract}
This report was prepared as an account of work sponsured by an agency of the United States Government. Neither the United States Gnvernment nor any agency thereof, nor any of their employees, makes any watranty, express or implied, or assumes any legal liability or responsibility for the accuracy, completeness, or usefulness of any information, apparatus, product, or process disclosed, or represents that its use would not infringe privately owned rights. Reference herein to any specific commercial product, process, or service by trade name, trademark, manufacturer, or otherwise does not necessarily constitute or imply its endorsement, recommendation, of favoring by the United States Government or any agency thereof. The views and opinions of authors expressed herein do not necessarily state or reflect those of the United States Government or any agency thereof.
\end{abstract}

June 1992 


\section{Disclaimer}

This report was prepared as an account of work sponsored by an agency of the United States Government. Neither the United States Governinent nor any agency thereof, nor any of their employees, makes any warranty, express or implied, or assumes any legal liability or responsibility for the accuracy, completeness, or usefulness of any information, apparatus, product, or process disclosed, or represents that its use would not infringe privately owned rights. Reference herein to any specific commercial product, process, or service by trade name, trademark, manufacturer, or otherwise, does not necessarily constitute or imply its endorsernent, recommendation, or favoring by the United States Government or any agency thereof. The views and opinions of authors expressed herein do not necessarily state or reflect those of the United States Government or any agency thereof. 


\title{
GRADIENT AND HARMONIC FIELD MEASUREMENTS OF THE 4Q120 QUADRUPOLE
}

\author{
Anthony J. Malensek
}

May 22, 1992

\section{Abstract}

The magnetic field gradients as well as the harmonics of two 40120 quadrupoles were measured utilizing a rotating coil system at Fermilab's MTF. One magnet was from the 1975 Series, and another from the TeV II Series. For excitation currents where the remnant field is a small fraction of the total, values of the absolute gradient for the latter magnets are typically $2 \%$ lower. Among the harmonics, the skew sextupole component has the highest value for both magnets. The harmonic measurements show small differences between the "power" and "return" ends of the magnet.

\section{Gradient Measurements}

Magnetic field measurements were taken on two 4Q120 quadrupoles. See Figure 1a. The first magnet (FRD10751 in the Research Division Numbering System) is one of a series fabricated by Industrial Coils Inc. of Middleton, Massachusetts in 1975. It's label reads "4Q120/1550, serial number 1011, 4/28/75". The second magnet (FRD11436) was manufactured as part of the $\mathrm{TeV}$ II upgrade in 1985, and carries a Fermilab Technical Support label reading "Tev II 4Q120, TV2-018, 5/16/85".

Typically the two series of magnets are taken to be equivalent, and are used interchangeably. The laminations are identical and the length of steel for each of them is 120 inches. The copper coils and the amount of insulation are slightly different. ${ }^{1}$ The two different types can be distinguished physically in that the TeV 11 magnet has an additional $3 / 8$ inch thick steel plate on all four sides of the outside case which serve in

\footnotetext{
${ }^{1}$ See Technical Services drawings 2221-MD-27384, 2221-ME-27703, 2221-MD-27483, and 2221-ME-27472.
} 
place of the fillet weld. The 1975 series uses butt welds to hold the case together. In addition, there are other physical differences in appearance. The 1975 series are painted dark orange, but some are brown, and they have tan coil packs having indentations separating the four quadrants. The TeV II series are painted light orange, they have white coil packs and the indentations between quadrants is filled in.

The measurements were taken ai the Fermilab Magnet Test Facility (MTF) using a rotating Morgan coil.2 The coil had the capability to measure the following Poles--2P, 4P, 6P, 8P, 10P, 12P, and 20P. All of these separate coils were mounted on a glass-epoxy (G10) cylinder with the wires at a radius of $34.5 \mathrm{~mm}$. The active length for the coils is approximately $943 / 8$ inches (the various separate harmonic coils differ. only by several wire diameters which altogether is less than $1 / 8 \mathrm{inch}$ ).

Since the 4Q120 magnet is longer than the Morgan coil, the procedure for obtaining $\int G$ dl was to combine two sets of measurements, one from each end of the magnet to cover the whole length. Figure $1 \mathrm{~b}$ and 1c illustrate the principle.

On one end, the probe is connected to a motor drive which rotates the coil through the magnetic flux. This end has the capability to be moved in the X-Y plane so the probe can be centered. The other end of the probe is held in place by an aluminum support block that fits into the bore tube of the 4Q120. The support block holds a bearing, and also contains a series of set screws to assure the probe is geometrically centered.

Measurements from the $2 \mathrm{P}$ pickup showed that the probe was aligned. The amount the probe extended inside the magnet was determined by measuring the length remaining outside the steel and subtracting that length from $943 / 8$ inches.

For quadrupole measurements the information came from the coil known as " $q 1$ ", the fourth wire from the inside of the probe. See Figure $1 \mathrm{~b}$ or 1c. Measurements of the current came from a transducer monitoring the power supply which has an absolute calibration better than $0.1 \%$. After setting the current, a complete set of measurements were taken at the power end with the probe setup in configuration $1 \mathrm{~b}$. To take the return end measurements, the magnet was not rotated $180^{\circ}$, rather the probe was changed into that shown in Figure 1c. An extension rod is added to the motor end, and the aluminum support block changes ends. The end that was supported by the aluminum block now protrudes outside the other end of the magnet where it is connected to a support having $X-Y$ adjustments.

2G. H. Morgan, "Stationary coil for measuring the harmonics in pulsed transport magnets." In Eounth International Conference on Magnet Technology, held at Brookhaven 1974, page 787. 

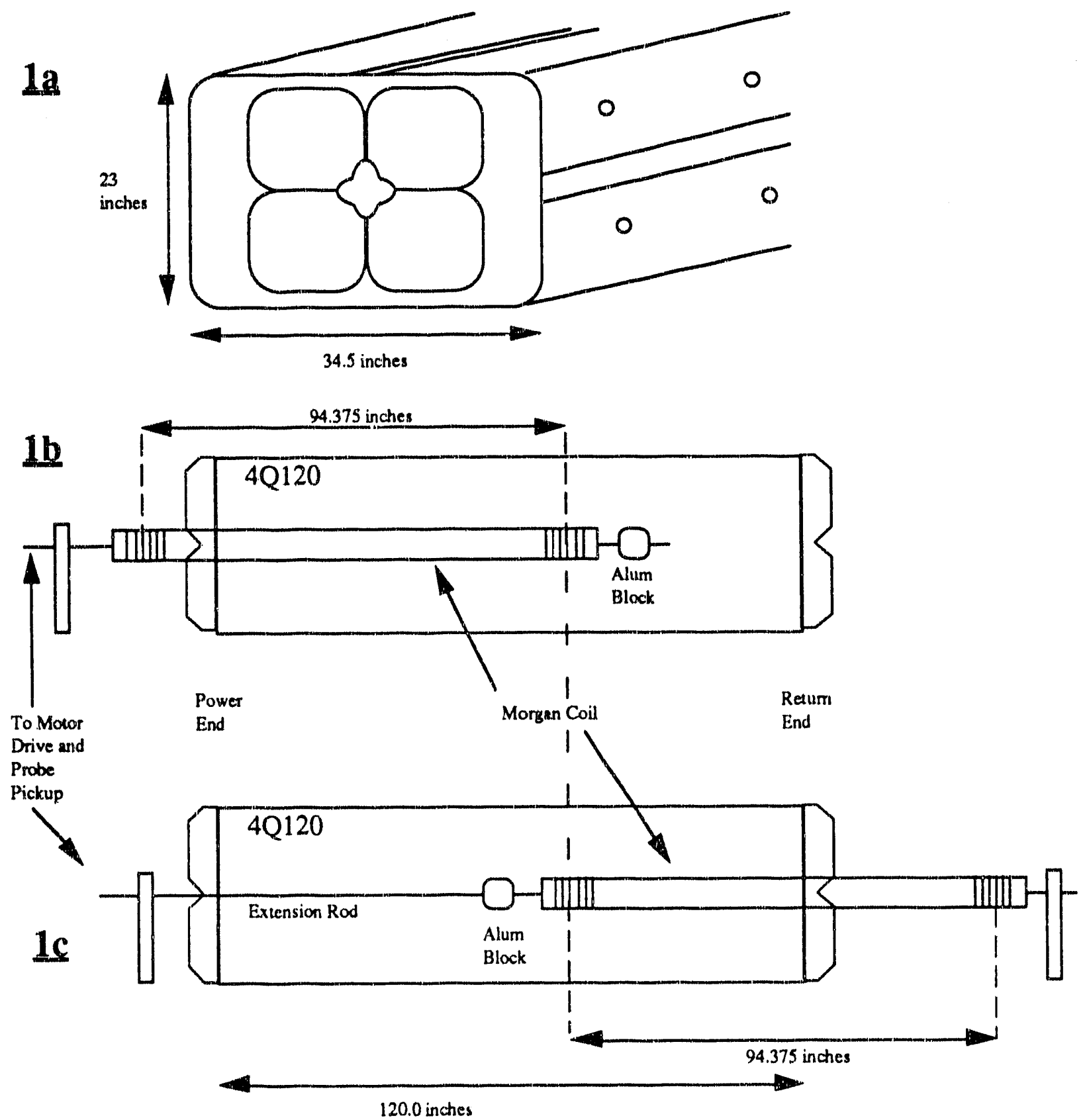

Figure 1 
For magnet FRD10751, the following individual measurements of $\int G$ dl were made:

Measurement (1)--probe reaching 60.5" into the steel at the "power" end. Measurement (2)--probe reaching $59.5^{\mathrm{n}}$ into the steel at the "return" end. Measurement (3)--probe reaching $80.0^{\prime \prime}$ into the steel at the "power" end. Measurement (4)--probe reaching 40.0" into the steel at the "return" end. Measurement (5)--probe reaching 10.0" into the steel at the "return" end.

For magnet FRD11436, the individual measurements of $\int G$ dl were:

Measurement (6)--probe reaching 60.0" into the steel at the "power" end. Measurement (7)--probe reaching 60.0" into the steel at the "return" end.

The measurement dates for $\left(59.5^{\prime \prime}+60.5 "\right),\left(80.0^{\prime \prime}+40.0 "\right)$, and $\left(60.0^{\prime \prime}+60.0^{\prime \prime}\right)$ were $5 / 2 / 90,5 / 9 / 90$, and 5/16/90 respectively. TABLE 1

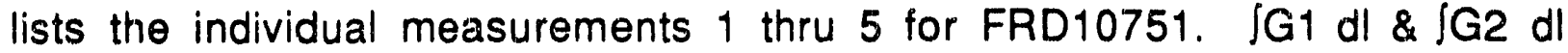
columns give the sum of the corresponding "power" plus "return" ends yielding $\int G$ dl for the entire quadrupole. The integrated $\left(59.5^{\prime \prime}+60.5^{\prime \prime}\right)$ measurement compares favorably with the $\left(80.0^{\prime \prime}+40.0 "\right)$ measurement. Except at very low currents, there is less than $0.1 \%$ difference between the two measurements over the full range of excitation currents.

TABLE 2 lists the measurements for FRD11436. It has a greater remnant field and also a smaller slope in the linear region than FRD10751. In addition, at high currents where the remnant contributes very little to the total gradient, the same amount of current gives less JG1 dl than FRD 10751, being uniformly lower by as much as $2 \%$. All data were taken sequentially both on the up-ramp 0-1900 amps and the down-ramp 1900-0 amps, without going back to zero between the individual measurements. One should keep in mind that even though there are measurements as high as 1900 amps, the magnet was not designed to operate routinely at these values because the cooling is inadequate. The magnet was designed to run at 50 kwatts DC at about 1200 amps.

Taking the length of a $4 Q 120$ as 120.0 inches, the data can be put into a form that is most commonly used by beamline physicists--gradient ( $\mathrm{kg} / \mathrm{inch}$ ) vs. current. Figure 3 shows this graphically. Saturation begins in the 800 to $900 \mathrm{amp}$ region and becomes most pronounced at the highest current of 1900 amps. The linear region is well described by :

FRD10751 (Early Series)

FRD11436 ( $T e V$ II Series)
$\mathrm{I}(\mathrm{amps})=-9.8+193.4{ }^{*} \mathrm{G}(\mathrm{kg} / \mathrm{inch})$

$\mathrm{I}$ (amps) $=-37.8+197.0^{*} \mathrm{G}(\mathrm{kg} /$ inch $)$

$4 Q 120$ length $\equiv 120.0$ inches 


\section{Eringe Field}

In actuality the magnetic length of the 40120 changes with current. Measurements on the "return" end previously listed as (2), (4), and (5), can be used to separate out the effective length into a length inside the steel and an average length in the air due to the fringe field.

$\mid($ effective $)=I($ stee $)+I($ fringe $)$

Taking all the measurements at the same end of the magnet so systematics are not an issue, the $\int \mathrm{G}$ dl values at 10", 40.", and 59.5" can be used to separate the individual measurements into the so-called body gradient (GO) times l(effective). For each current, a straight line fit is made using the lengths 10.", 40.", and 59.5" as one axis and $\int G \mathrm{dl}=\mathrm{R}(10 . ")$, $\int G d l=R(40 . ")$, and $\int G d l=R\left(59.5^{\prime \prime}\right)$ as the other axis.

$$
R(I)=m l+b
$$

For example, at the nominal 800 amps $R(I)=24.714=0.41057^{\star} \mid+0.2776$, $I=59.5$. The slope of this line, $m$, is the body gradient $\mathrm{GO}$. Both $\mathrm{m}$ and $\mathrm{b}$ vary with the current-- $m(i)$ and $b(i)$. Substituting the various $m$ values gives l(fringe) as a function of current.

$$
\begin{aligned}
& R(\text { steel })=G O^{*}[\mid(\text { effective })]=m^{*}[\mid(\text { stee })+1(\text { fringe })] \\
& I(\text { fringe })=\{[R(\text { stee })] / m\}-I(\text { stee })
\end{aligned}
$$

Of the three measurements at each current, the one having the smallest percentage error is at $R\left(59.5^{\prime \prime}\right)$, because it has the largest absolute value. However, since $R\left(59.5^{\prime \prime}\right)$ was not measured at the nominal 900 amps, to include it on the plot, it was calculated by the average straight line ratio between the nominal 800 and 1000 amps, and then relating $R(59.5 ")$ and $P\left(60.5^{\prime \prime}\right)$.

$$
R\left(59.5^{\prime \prime}\right)=(27.830)\left[\left(\frac{24.714}{25.136}+\frac{29.546}{30.064}\right) / 2 .\right]=27.357 \quad @ 900 \text { amps. }
$$

Excitation current is then plotted versus l(fringe).

$$
I(\text { fringe })=\left\{R\left(59.5^{\prime \prime}\right) / \mathrm{m}(i)\right\}-59.5^{\prime \prime}
$$


A graph of

I(fringe) at each end

of the magnet as a

function of current is

shown in Figure 2.

Thus at low currents

the effective length

is about 121.6 inches.

This gives a

quantitative feel for

how far the field

effectively extends

outside the magnet,

keeping a constant

gradient. The

decrease in effective

length as a function

of excitation current

can be understood as

a saturation

phenomena. When the steel is unsaturated, almost all the field lines in the air just beyond the magnet are generally parallel to the steel, and thus have a significant component in the same direction as the body of the magliet.

In saturation, the

lines "bulge" out

further and further into the air, giving a longer path length and also having both parallel and perperidicular components with respect to the body. As a result, when the probe measures the field integral, the amount adding in the same direction as the body of the magnet is reduced compared to when the lines have a short path and are essentially parallel to the face.

This should not be confused with the previous section where fits were done defining l(effective) to be 120.0 inches. It is common practice to take l(effective) constant as the length of the steel and include the varying part along with the gradient.
Versus

Current

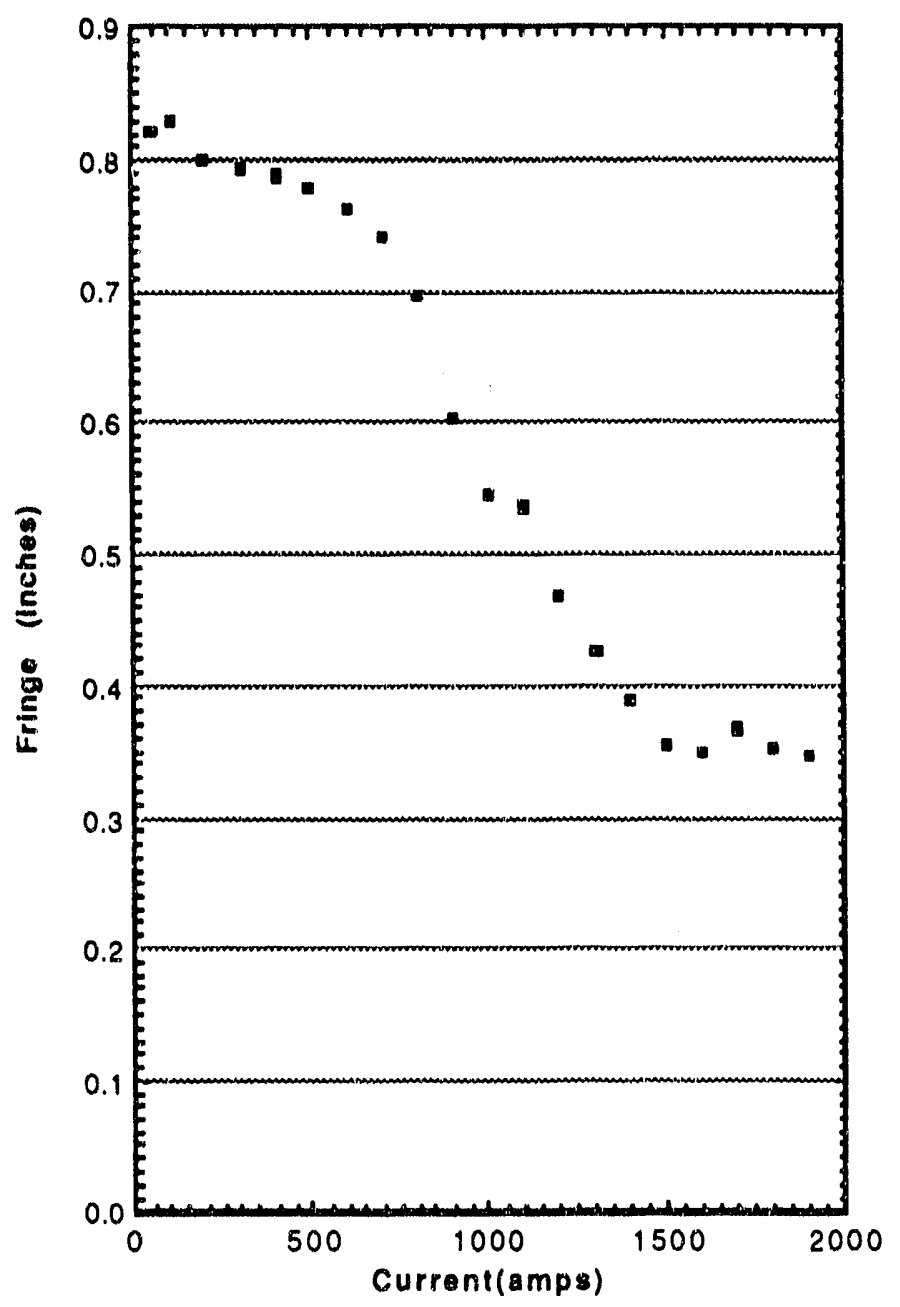

Figure 2 


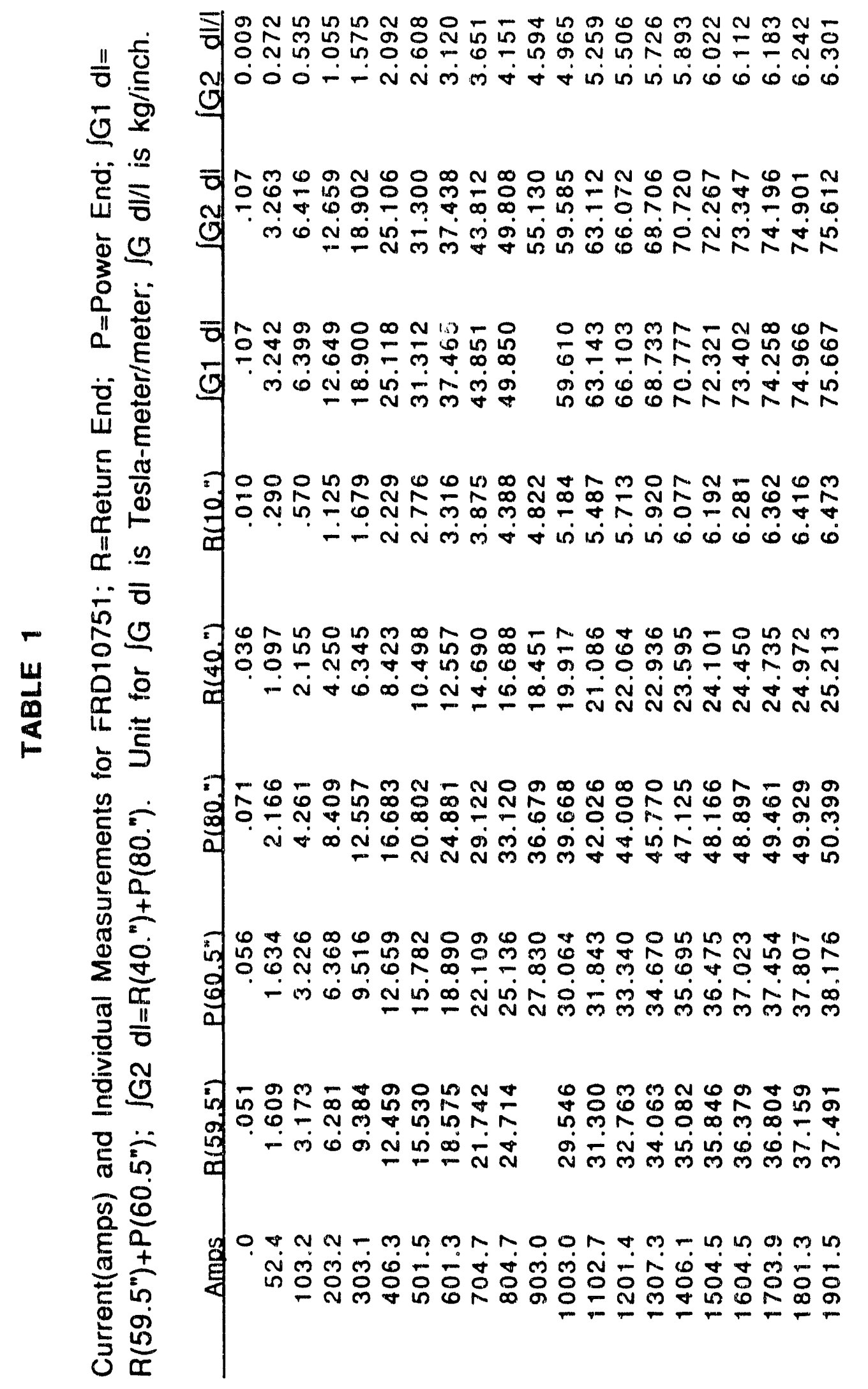

$-m-N-\infty a-\infty$ $\infty N m N N \frac{1}{4}$ क - ONN 000 in $\dot{0} \dot{0}$ மं

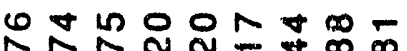
- Nล

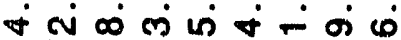
NN⿻

$\forall \sigma-\sigma m+\omega * n$

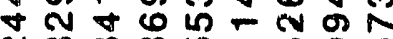
N ल $\infty$ ल $\forall N \infty$ का

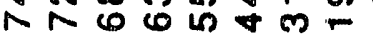

- $\sigma N \omega N m$

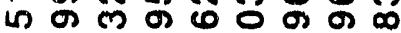

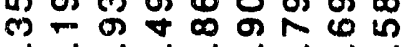
ம $\dot{0}$ in

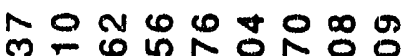
$N=\infty \pi$ in $\infty$ in $\&$

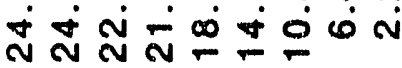

क $\forall \forall \forall m+0=$ $m \omega \div \infty \frac{1}{2} \infty \pi$ $\forall-\infty=0$ क ल or $\infty$ in 0 i 0 i $\forall \forall \forall M N$ N

$N \infty 0 N-\infty N N a$ $\forall N N$ in $N$ m 0 $\forall \forall r \infty 0 N \infty \omega$ $\therefore \dot{\sigma}^{\circ}-\infty$ N ल ल ल N N =

क $\Lambda \infty-\nabla$ in $\infty$ i ம் में

m 2 NOON

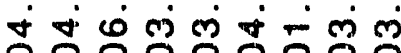
00000000 


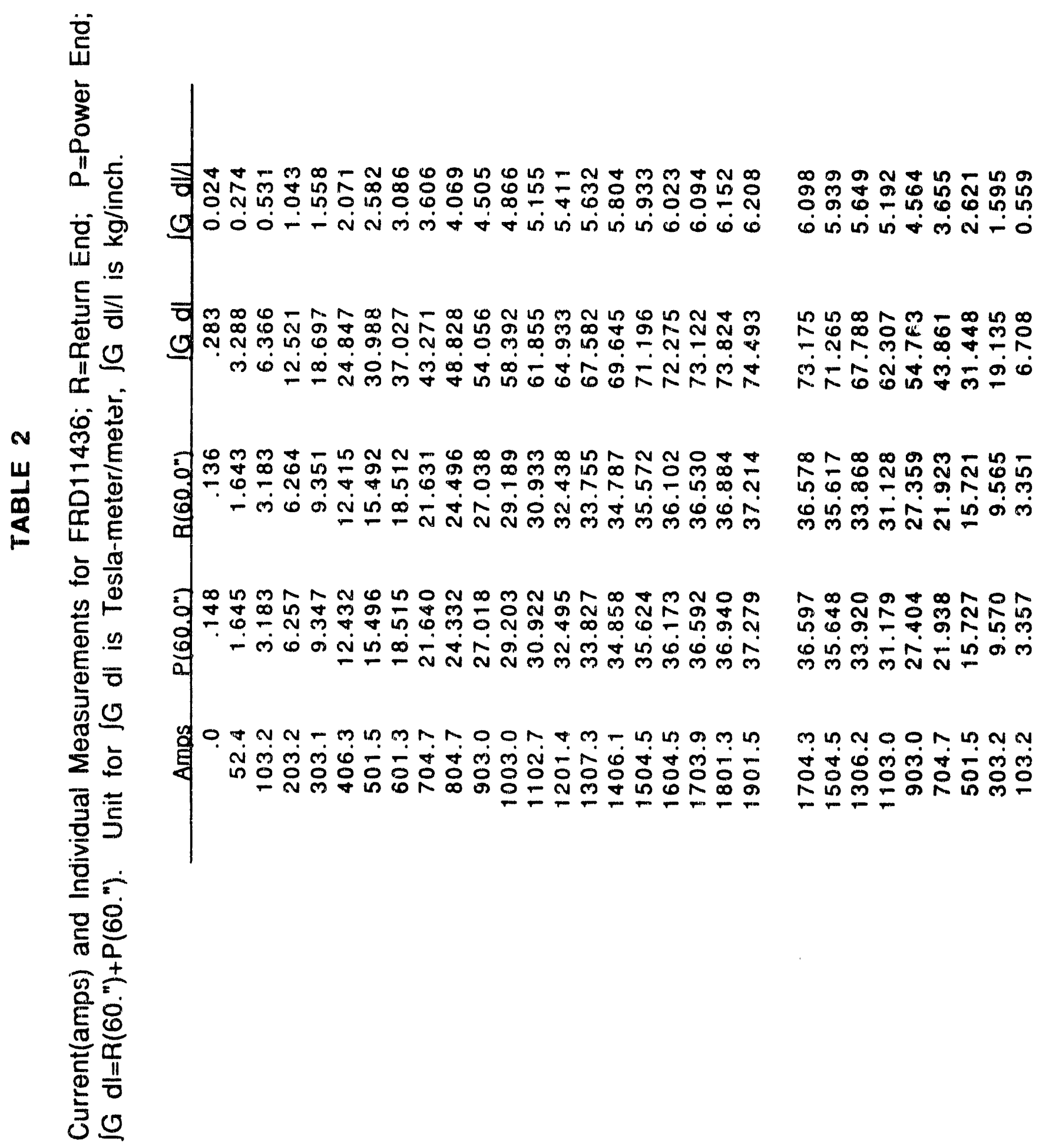




\section{Q120 Quadrupole Field vs. Current}

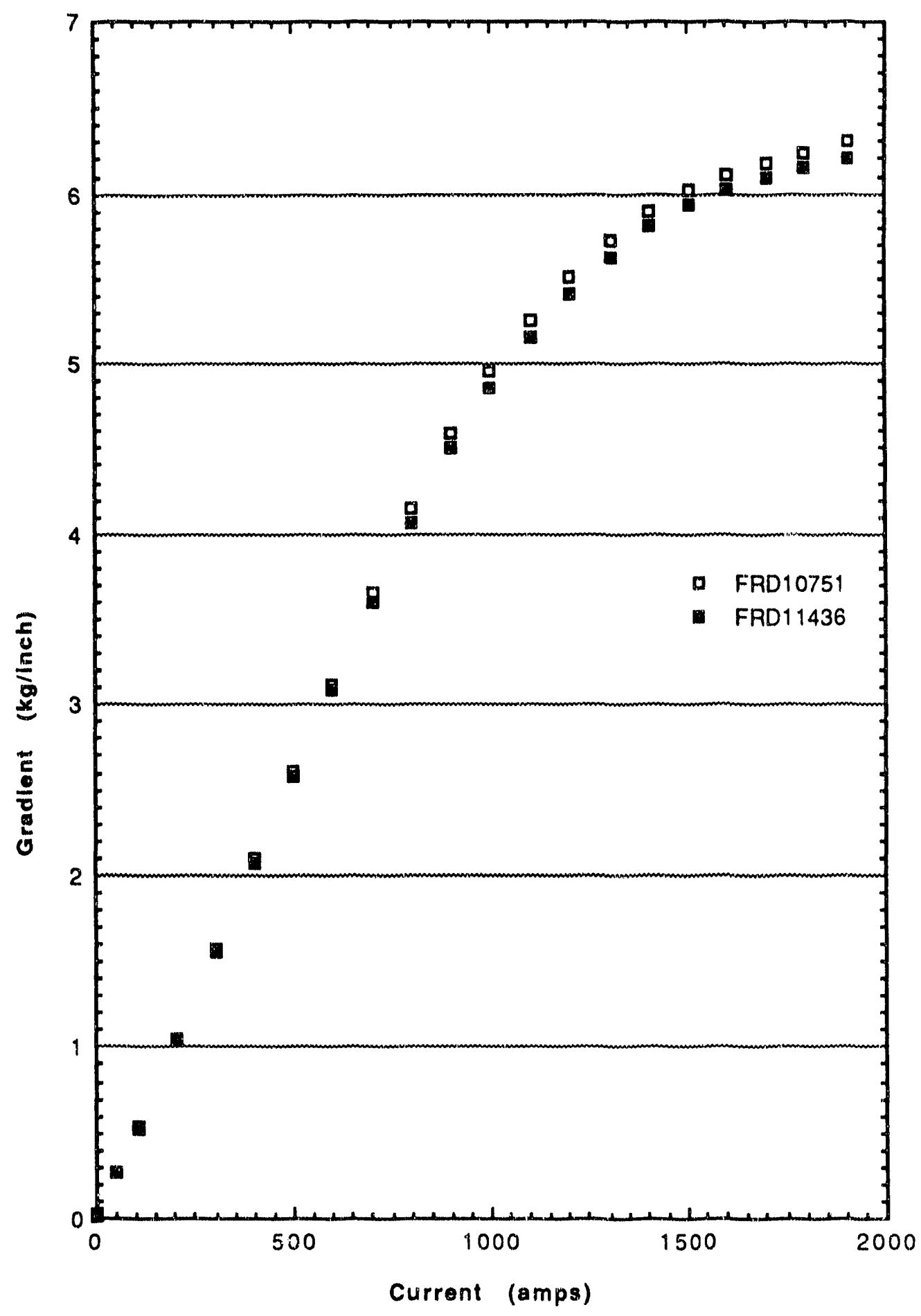

Figure 3 


\section{Harmonic Measurements}

In addition to measuring the quadrupole field as a function of current, harmonic measurements were made on both magnets at 600 , 1200 , and 1600 amps.

The harmonic measurements were taken on both the power and return ends for each of the quadrupoles at their $=60$ inch probe values. This was done at three different currents--600, 1200, and 1600 amps. The measurements were analyzed in terms of a two-dimensional harmonic representation

$$
B=B_{y}+i B_{x}=\sum_{J=1}^{\infty}\left(C_{N} a^{N-1}\right)\left(\frac{r}{a}\right)^{(J-1)} c_{J} e^{i\left((J-1) \theta+\chi_{J}\right)}
$$

in which $B_{y}$ and $B_{x}$ are components of the magnetic field, $C_{N}$ is the harmonic field of the dominant field component ( $N=2$ for quadrupoles), and $a$ is the reference radius. Characterizing the shape imperfections of the field by comparing them to the dominant harmonic components leads to a definition of the normalized harmonic coefficient $c_{J}$

$$
c_{J}=\frac{C_{J} a^{J-1}}{C_{N} a^{N-1}}=\frac{C_{J} a^{J-N}}{C_{N}} \quad c_{J} e^{i\left(x_{J}\right)}=\left(b_{J}+i a_{J}\right)
$$

Some symmetry properties are most easily seen by separating the normalized coefficient into ("normal" $\equiv b_{j}$ ), and ("skew" $\equiv a_{j}$ ) terms.

$$
b_{J}=c_{J}{ }^{*} \cos \chi_{J} \quad a_{J}=c_{J}{ }^{*} \sin \chi_{J}
$$

$c_{J}, x_{J}$ are the normalized harmonic coefficient and its phase. $b_{J}$ and $a_{J}$ are the corresponding normal and skew normalized harmonic coefficients. $r$ and $\theta$ are the cylindrical position coordinates and $a$ is the reference radius at which the harmonic coefficients are normalized. The quadrupole field is the angular reference and is assumed it has no skew quadrupole $(\chi=0)$. Since the measurements were made with a coil having a radius of $34.5 \mathrm{~mm}$ and it is customary to give the results at a reference radius of 1.0 inch, the calculated $b_{j}$ and $a_{J}$ were converted from the measured $c_{J}$ by, 
$c_{J}^{a}=c_{J}^{A}\left(\frac{a}{A}\right)^{J-N}$

Substituting $N=2 . A=34.5, \& z=25.4$ for a quadrupole, the harmonic coefficients at a radius of 1.0 inch for each magnet are yiven below in units * (1.0E4):

FRD 10751

Return End

Power End

\begin{tabular}{ccrrrr} 
Amos & Pole & Normal & Skew & Normal & Skew \\
\hline 600.0 & $6 P$ & 0.49 & 1.44 & 0.14 & 1.70 \\
600.0 & $8 P$ & 1.35 & 0.82 & 2.70 & 0.07 \\
600.0 & $10 P$ & 0.35 & -0.59 & 0.21 & -0.58 \\
600.0 & $12 P$ & -1.93 & -0.11 & -1.78 & 0.01 \\
600.0 & 20P & 0.11 & 0.01 & 0.11 & 0.00 \\
1200.0 & $6 P$ & -2.35 & 6.61 & 0.10 & 6.70 \\
1200.0 & $8 P$ & 1.62 & 0.62 & 2.92 & 0.01 \\
1200.0 & $10 P$ & 0.20 & -0.65 & 0.13 & .0 .63 \\
1200.0 & $12 P$ & -1.75 & -0.10 & -1.62 & 0.02 \\
1200.0 & $20 P$ & 0.10 & 0.01 & 0.10 & 0.00 \\
1600.0 & $6 P$ & -4.22 & 6.71 & -0.53 & 5.93 \\
1600.0 & $8 P$ & 1.70 & 0.59 & 2.93 & 0.00 \\
1600.0 & $10 P$ & 0.11 & -0.64 & 0.11 & -0.58 \\
1600.0 & $12 P$ & -1.89 & -0.16 & -1.78 & 0.01 \\
1600.0 & 20P & 0.09 & 0.00 & 0.09 & 0.01
\end{tabular}

FRD11436

Return End

Power End

\begin{tabular}{rcrrrr} 
Amps & Pole & Norma! & Skew & Normal & Skew \\
\hline 600.0 & $6 P$ & 2.27 & 2.30 & 0.18 & 1.68 \\
600.0 & $8 P$ & -6.32 & -0.30 & -9.19 & -0.26 \\
600.0 & $10 P$ & 0.16 & -0.15 & 0.07 & -0.29 \\
600.0 & $12 P$ & -1.74 & -0.02 & -1.82 & -0.03 \\
600.0 & $20 P$ & 0.10 & 0.00 & 0.10 & 0.00 \\
1200.0 & $6 P$ & 5.09 & 8.69 & -0.12 & 8.78 \\
1200.0 & $8 P$ & -6.24 & -0.30 & -8.99 & -0.15 \\
1200.0 & $10 P$ & 0.30 & -0.30 & 0.10 & -0.47 \\
1200.0 & $12 P$ & -1.64 & -0.10 & -1.71 & -0.03 \\
1200.0 & $20 P$ & 0.09 & 0.01 & 0.09 & 0.00 \\
1600.0 & $6 P$ & 3.08 & 9.12 & -4.28 & 11.29 \\
1600.0 & $8 P$ & -6.24 & -0.24 & -8.95 & -0.16 \\
1600.0 & $10 P$ & 0.23 & -0.34 & -0.01 & -0.55 \\
1600.0 & $12 P$ & -1.75 & -0.04 & -1.81 & -0.03 \\
1600.0 & $20 P$ & 0.09 & 0.01 & 0.09 & 0.00
\end{tabular}




\section{Summary}

Magnetic field measurements have been made on the "Early" Series and the "TeV II" Series 4Q120 quadrupoles. The technique of combining separate measurements when the physical probe is shorter than the magnet works well. Errors can come from (1) the accuracy of positioning the probe, (2) the current measurement, and (3) the electronics measuring the induced EMF. In our particular situation, the largest error came from the first item. The probe was positioned in $Z$ to $\pm 1 / 15$ inch, which was easy to accomplish. This translates into a maximum erior of $0.125 " 1120$." $\approx 0.1 \%$, and in fact for the same magnet the $\left(59.5^{\prime \prime}+60.5^{\prime \prime}\right)$ measurement came out within $0.1 \%$ of the $\left(80.0^{\prime \prime}+40.0^{\prime \prime}\right)$ measurement.

Beam optics requiring high precisic.l should be careful not to connect the two different quadrupole types in series to the same power supply. Treating the two Series interchangeably could lead to as much as a $2 \%$ error. The linear regions for the two Series are well described by,

FRD10751 (Early Series)

FRD11436 (TeV II Series) $\mathrm{l}(\mathrm{amps})=-9.8+193.4{ }^{*} \mathrm{G}(\mathrm{kg} / \mathrm{inch})$

$l($ amps $)=-37.8+197.0^{*} \mathrm{G}(\mathrm{kg} / \mathrm{inch})$

$1 \leq 800$ amps: Length $\equiv 120$. inches

Beyond 800 amps, for interpolation purposes, taking the same length, $L \equiv 120.0$ inches, Table 1 and Table 2 cin be converted into practical units by dividing the $\int G \mathrm{dl}$ columns by 12 . This then gives current(amps) in the first column and the gradient ( $\mathrm{kg} / \mathrm{inch}$ ) in the last column, the same units as are used in Figure 3.

The contribution from the fringe field to $\int G \mathrm{dl}$ is small. The effective lengti: varies from 121.6 inches at low currents to 120.7 inches at high currents. Considering the $4 \mathrm{Q} 120$ has a maximum full aperture over 4 inches, such small distances beyond the steel length of 120 . inches are quite good.

Over all the harmonics, both the "normal" and "skew" sextupole components are largest for both magnets. Of the "normal" and "skew" components, the "skew" is uniformly larger. The "TeV II" Series also has a large normal octupole component compared to the "Early" Series.

\section{Acknowledgments}

I am grateful for the experience and expertise of David Hartness and Shree Agrawal of MTF for carrying out the measurements. I have also profited from helpful discussions with Bruce Brown, Alan Wehmann, Fred Mills and Bob Peters. 

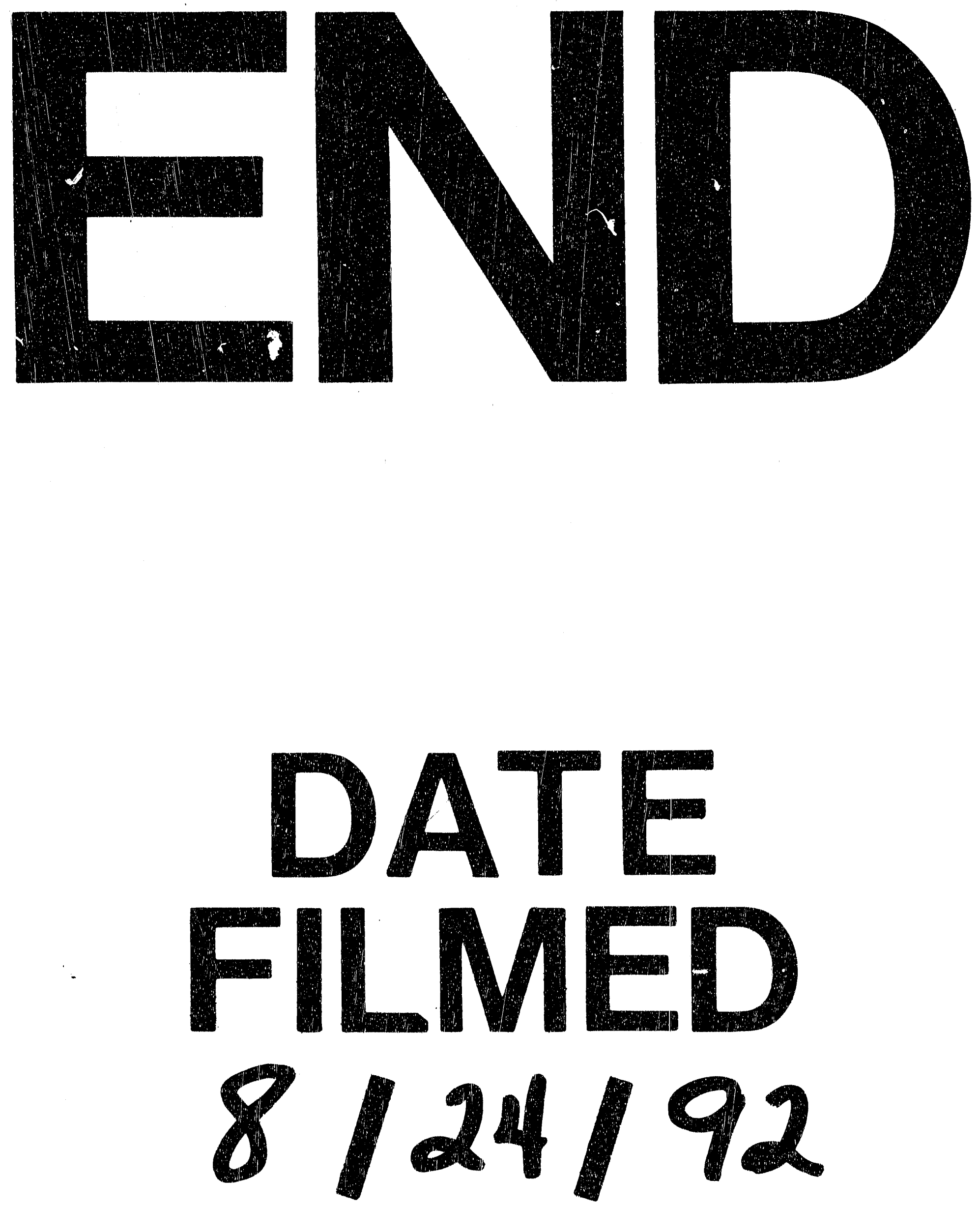
